\title{
DEVELOPING COMPETENCIES FOR THE DENTAL CARE OF PEOPLE WITH SENSORY DISABILITIES: A PILOT INCLUSIVE APPROACH
}

\begin{abstract}
Objectives: Different training programs for healthcare students that have a biopsychosocial approach have been reported to have a significant beneficial impact on their education, attitudes and competencies towards Persons with Disabilities. In Chile, however, there are no explicit legal obligations to provide healthcare professionals with the skills required to offer their services in public or private healthcare facilities to Persons with Disabilities. Given this situation, a pilot onesemester elective course for dental students was carried out focusing on people with visual disabilities and people with hearing disabilities, incorporating Deaf and blind teachers. The aim of this paper is to describe the perceptions and results of this pilot course aimed at identifying and responding to the healthcare needs of people with visual or hearing disability pilot one-semester elective course for dental students was carried out focusing on people with visual disabilities and people with hearing disabilities, incorporating Deaf and blind teachers.
\end{abstract}

Materials and methods: A multi-strategy 17-week elective course was carried out in the first semester of Dentistry School with 14 students enrolled. Educational strategies used were lectures, guided discussion (GD), role-play (RP), standardized patients (SP) and case method teaching (CM), with the participation of Deaf and blind teachers. Once the program had finished, the students answered a survey designed with openended questions, and GD, RP, SP, CM, attendance and grades obtained were recorded and analyzed.

Results: Attendance was $82-100 \%$. All students passed the course with the highest score, and thus were able to define the medical approach needed in cases of hearing and visual disability, recognize the cultural and linguistic aspects of people with visual disability and people with hearing disability and learn their means of communication.

Conclusions: This course was successful in helping the students to identify and respond to the healthcare needs of people with visual or hearing disability.

Key Words: Sign language, braille, students, dental.
*Valeria Campos ${ }^{1}$

Ricardo Cartes-Velásquez ${ }^{2,3}$

ORCID IDs of the authors:

V.C. $\quad 0000-0003-0697-1345$

R.C.V. 0000-0001-5831-7324

1 Departamento de Prevención y Salud Pública Odontológica, Facultad de Odontología, Universidad de Concepción, Concepción, Chile.

2 Facultad de Odontología, Universidad Andrés Bello, Concepción, Chile.

${ }^{3}$ Fundación Kimntrum, Concepción, Chile.

How to Cite: Campos VA, Cartes-Velásquez R. Developing Competencies for the Dental Care of People with Sensory Disabilities: A Pilot Inclusive Approach. Cumhuriyet Dent J 2020;23:2;107-115.

*Corresponding Author:

Departamento de Prevención y Salud Pública Odontológica, Facultad de Odontología, Universidad de Concepción, Avenida Roosevelt \#1550, Concepción, 4070369, Chile.

Email: valeriacamposcannobbio@gmail.com 


\section{INTRODUCTION}

The current biomedical approach does not encourage the inclusion of People with Disabilities, as it places the disability within the person, rather than seeing it as the result of the interactions between the person and the environment. ${ }^{1,2}$ According to the World Health Organization, Persons with Disabilities are two times more likely to find that health-care providers' skills do not meet their needs and three times more likely to report being denied healthcare. ${ }^{3}$ One of the main reasons for this situation is the lack of training in healthcare professionals regarding subjects such as how to address Persons with Disabilities and the use of a more bio-psychosocial approach, which would satisfy the health-care needs of everyone, including Persons with Disabilities. ${ }^{4}$ In dental health, patients with sensory disabilities have a high prevalence of dental caries and poor oral hygiene. ${ }^{5}$

Visual and hearing disabilities are two of the most prevalent disabilities around the globe, ${ }^{6}$ and according to Bachmann, patients with these disabilities are the most complex population for healthcare providers due to communication barriers. ${ }^{4}$ People with an early onset of moderate to profound hearing loss usually call themselves "Deaf" and define themselves as part of a community with its own culture, values and language, where sign language (SL) is their most important cultural element. ${ }^{7,8}$ People with a visual disability use different devices for reading and writing; people with congenital blindness usually use Braille, screen readers and voice recognition. ${ }^{9}$ People with low vision use optical or electronic magnifiers, prisms, screen readers and voice recognition. It is important to highlight that SL and Braille are recognized worldwide. ${ }^{9-12}$

Different training programs using a biopsychosocial approach have been reported to have a significant beneficial impact on healthcare students around the world in terms of their education, attitudes and competencies towards Persons with Disabilities. ${ }^{13-20}$ Regarding teaching strategies, it has been established that lectures, guided discussion, role-play, standardized patients and case method teaching are effective in promoting critical thinking in healthcare students. ${ }^{15,19,21-23}$

In Chile, even though there are no explicit legal obligations to provide healthcare professionals with the skills required to offer their services in public or private healthcare facilities to Persons with Disabilities, ${ }^{24}$ to our knowledge, every year more universities incorporate courses to develop such skills among their students. However, most of these courses tend to cover all disabilities in one semester or year and do not usually include the active participation of Persons with Disabilities. ${ }^{22}$

Given this situation, a pilot one-semester elective course for dental students was carried out focusing on people with visual disabilities and people with hearing disabilities, incorporating Deaf and blind teachers.

The aim of this paper was to describe the perceptions and results of this pilot course aimed at identifying and responding to the healthcare needs of people with visual or hearing disability.

\section{MATERIALS AND METHODS Design and population}

Approval was obtained from the Commission of Research and Bioethics of the School of Dentistry of the Universidad de Concepción, Chile, and the participants gave their informed consent before the study began.

This was a case study of an elective course aimed at identifying and responding to the healthcare needs of people with visual or hearing disability. The participants were undergraduate dental students in their $2^{\text {nd }}$ to $5^{\text {th }}$ year. The elective course, for 14 students, was one of the elective courses offered by the School of Dentistry, via which they earned course credits. There were no other selection criteria.

\section{Elective course description}

The expected learning outcomes of the pilot course were:

1. To define the medical approach towards hearing and visual disability. 
2. To recognize the cultural and linguistic aspects of people with visual disability and people with hearing disability.

3. To learn the means of communication of people with visual disability and people with hearing disability.

A multi-strategy 17-week elective course was carried out in the first semester of the Dentistry School, with 14 students enrolled. All agreed to take part in the study. The course involved a twohour lecture plus a two-hour home assignment per week. For evaluations, the Chilean grading system was used, which ranges from $1.0-7.0$, where 4.0 is needed to "pass".

The course was divided into three stages. The first class was introductory, during which the course program, expected learning outcomes, contents, methodology, length of the course and evaluation system were discussed with the students. All PowerPoint material, the syllabus, instructions, rubrics and additional material such as the Convention on the Rights of Persons with Disabilities, and official national laws regarding people with disabilities, among others, were available in a virtual library. Additionally, a WhatsApp group was created between the students and the teacher (VC) in order to facilitate fluent communication.

First stage: Classes $2-5$

1. Role-playing: This activity was based on the Deaf Strong Hospital program which mimics actual healthcare scenarios in a Public Family Health Center (Centro de Salud Familiar, CESFAM). ${ }^{19}$ After each role-playing activity, debriefing sessions were carried out, in which the students reported their personal experience.

a. First, students experienced deaf people's barriers in healthcare. Each student received individual written and oral instructions for the activity. Different health scenarios were assigned randomly, and medical exam documents and a Fingerspelling alphabet were handed to each student. Each student had to enter the conditioned classroom and wait in the waiting room where he/she had to communicate with a Deaf SL user receptionist, physician and pharmacist. In each scenario, the receptionist called out the student's name by fingerspelling and asked in SL the type of health insurance.

b. In the second role-play, students experienced blind people's barriers in healthcare. Each student received individual written and oral instructions for the activity. Different health scenarios were assigned randomly, and medical exam documents, a blindfold and a cane were handed to each student. Each student had to enter the conditioned classroom, wearing the blindfold and with the help of the cane, and wait in the waiting room where he or she had to communicate with a receptionist, physician and pharmacist. In each scenario the receptionist asked the student his/her name and type of health insurance and handed out a receipt to sign without offering any help or guidance.

\section{Guided discussion}

a. Movie analysis: The students' homework was to watch the Indian movie "Black" (https://www.imdb.com/title/tt0375611/), which addresses the life of a deafblind girl, inspired by Helen Keller's life and struggle. After watching the movie, they had to answer written reflective questions at home, and then discuss them in class. The main topics were "What was Michelle's childhood like before and after the arrival of the teacher?", "What did you like the most about the movie?", "What struck you the most about the movie?" and "Did the movie change your way of thinking about deafblind people?"

b. Article discussion: A copy of the brief Comment "Who has special needs?" 25 was handed to each student. After individual reading, a group discussion was carried out about the euphemism Special Needs and the term "Persons with Disabilities".

Second stage: Classes 6-10

1. Lecture: A traditional lecture was given by the teacher (VC) about the current approaches towards people with hearing or visual disability and their healthcare barriers.

2. Interactive class 1 : Led by a blind person. The topics were "How to approach a blind person" and 
"How to help a blind person to move around", addressed through a lecture and practical exercises. Students were challenged to guide the blind teacher and/or had to use a blindfold and receive instructions from a peer.

3. Interactive class 2: Led by a Deaf person. The topics were "How to approach a Deaf person" and "Deaf Culture", addressed through a lecture and practical exercises. Students were challenged to approach the deaf teacher in a Deaf-culturally accepted way.

4. Case Method Teaching Stage 1: Students were grouped in random pairs and had to visit a CESFAM to identify possible barriers for people with visual or hearing disability. They had to navigate through the CESFAM and interview the health staff, and had to take pictures of the possible barriers. For this activity students received constant feedback from the teacher (VC). Then they had to prepare an oral presentation of their visit, in which they had to define each of the barriers.

Third stage: Classes 11-17.

1. Braille lessons: Three practical classes were conducted by a blind teacher on this writing system. Students learnt the basics of Stage 1 of Braille. Each student was given a slate and stylus to practice in class and at home.

2. Braille practical exam: The fourth class was a practical exam, in which students had to write a medical prescription for a patient in Braille (Figure 1).

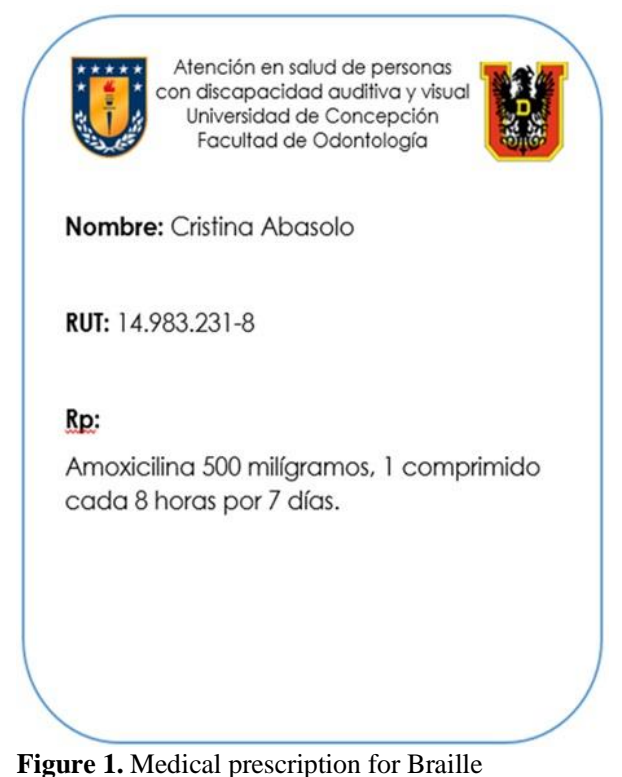

Figure 1. Medical prescription for Braille
3. Chilean Sign Language lessons: Three practical classes conducted by a Deaf teacher. Basic signs relating to a general clinical record and specific signs for dental examination were taught. Students had permission to record the teacher.

4. Standardized patients: For the Chilean Sign Language practical exam, the Deaf teacher took the role of a Deaf patient, based on a previous script written by the coordinating teacher. Students were given a clinical record (Figure 2), which they had to complete by asking questions in SL to their Deaf patient. Then, they had to communicate the diagnosis, treatment and the date for a follow-up appointment to the Deaf patient.

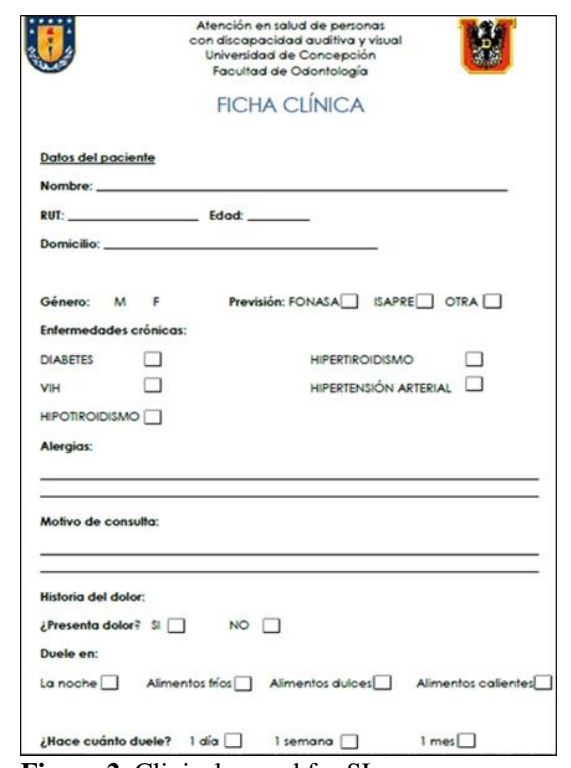

Figure 2. Clinical record for SL exam

5. Case Method Teaching Stage 2: The same pairs of students had to present reasonable adjustments to the previous barriers identified by them in the CESFAM. Before the oral presentation, students received constant feedback from the teacher (VC). Directors of the different CESFAMs were invited to attend this activity.

\section{Data collection}

Once the course had finished, the students answered a survey designed with open-ended questions, according to Castro et al. ${ }^{26}$, to determine if the new teaching intervention had led to any changes in their understanding of the approach of Persons with Disabilities. Students completed the anonymous questionnaire using the following open-ended questions: 1) "Do you think this course provided you with knowledge or experience that will help you as a 
professional? Please explain your answer."; 2) "In your opinion, what do you think was the most important aspect of the course that influenced your professional training? Please explain your answer." 3) "Suggestions and comments". Also, based on the Deaf Strong Hospital survey ${ }^{15}$, three questions on a Likert scale 1-5 were added to the survey, 1) "I learned valuable information through my participation in role-play"; 2) "My experience is likely to positively impact my attitudes and behaviors in future interactions with deaf or blind patients."; 3) "The role-playing time was used effectively".

In addition, guided discussions, case method teaching, standardized patients, attendance and grades obtained were recorded and analyzed.

\section{Analysis}

Descriptive statistics were used to analyze the students' scores, including average and range scores. Qualitative results were obtained through the identification of relevant quotes, which were grouped by topic.

\section{RESULTS}

Eight students had an attendance of $100 \%$, followed by three students with an attendance of $94 \%$, two with $88 \%$ and one with $82 \%$.

Quotes from the guided discussion are shown Table 1.

Table 1. Quotes from Guided Discussion from movie "Black"

\begin{tabular}{|c|c|}
\hline Questions & Quotes \\
\hline $\begin{array}{l}\text { How do you find Michelle's childhood } \\
\text { was before and after the arrival of the } \\
\text { teacher? }\end{array}$ & $\begin{array}{l}\text { Before arrival of teacher: "Very dark"; "Lonely"; "Isolated"; "She was } \\
\text { treated as an animal"; "Michelle just acted by instinct", } \\
\text { After arrival of teacher: "Stable life"; "She learnt how to communicate", } \\
\text { "Happy life"; "Was able to live life", }\end{array}$ \\
\hline $\begin{array}{l}\text { What did you like the most about the } \\
\text { movie? }\end{array}$ & $\begin{array}{l}\text { "The concept of learning and overcoming of Michelle"; "A critic and real } \\
\text { vision on how life is for a Deafblind person"; "That the teacher believed in } \\
\text { her"; "Michelle was able to be an independent person", }\end{array}$ \\
\hline $\begin{array}{l}\text { What struck you the most about the } \\
\text { movie? }\end{array}$ & $\begin{array}{l}\text { "Michelle's' childhood...her parents had forgotten she was a human } \\
\text { being", "To learn how a Deafblind person lives" }\end{array}$ \\
\hline $\begin{array}{l}\text { Did the movie change your way of } \\
\text { thinking about deafblind people? }\end{array}$ & $\begin{array}{l}\text { "No, but I did learn that Deafblind people crave for physical contact"; } \\
\text { "Frankly, this subject never came to my mind before watching this movie"; } \\
\text { "Yes, I had never dimensioned what it is to live in absolute darkness"; "We } \\
\text { usually think they are very dependable and feel pity, but they are just like } \\
\text { us"; "Yes, we should respect everyone, as everyone has the same Rights"; } \\
\text { "Yes, I realized that Deafblind people also want to achieve what we all } \\
\text { want, a profession, a family, etc." }\end{array}$ \\
\hline
\end{tabular}

All students agreed that the correct term is Persons with Disabilities, and not the current euphemism Special Care patients. They also internalized the concept that Persons with Disabilities are persons with Rights, and no longer of pity.

All students passed the Braille practical exam and the standardized patient practical exam.

Regarding Case Methods stages $1 \& 2$, the students correctly identified most of the barriers a person with visual or hearing impairment may encounter when visiting a CESFAM. They identified barriers based on scientific literature, their own experience in the role-play and the interactive classes. Also, they were able to identify reasonable adjustments to address the barriers identified. They identified the adjustments based on scientific and non-scientific literature.

Six students obtained a final grade of 7.0, and the remaining eight obtained a grade of 6.9.

Students' perceptions about the role-play and the course in general are shown in Tables 2 and 3. 
Table 2. Distribution of Dental students' evaluation of the Role-Play activity

\begin{tabular}{|c|c|c|c|c|c|}
\hline & $\begin{array}{l}\text { Strongly } \\
\text { Agree }\end{array}$ & Agree & Not sure & Disagree & $\begin{array}{l}\text { Strongly } \\
\text { Disagree }\end{array}$ \\
\hline $\begin{array}{l}\text { 1. I learned valuable information through my } \\
\text { participation in Role-play. } \\
\text { 2. My experience is likely to positively impact } \\
\text { my attitudes and behaviours in future } \\
\text { interactions with Deaf or Blind patients. }\end{array}$ & 14 & 1 & & & \\
\hline $\begin{array}{l}\text { 3. The role-playing time was used } \\
\text { effectively }\end{array}$ & 12 & 2 & & & \\
\hline
\end{tabular}

Table 3. Students quotes from open-end survey

"Totally, every day inclusion is stronger, so I feel the responsibility to know about it, and this course was the first encounter with inclusion in dentistry"

"I think it's one of the courses where I've felt the happiest. Every class I learnt something new about Deaf culture and people with visual impairments. This course has encouraged me to fight for a world without communication barriers"

"I think this course gave me knowledge and experience that will help me in the future because we faced situations for which most of us were not prepared and we learn how to solve them"

"Yes, it gave me so much knowledge that will help me in my future career, because I will be able to help people with sensory disabilities, and these people will feel more included by the health system. Besides, now I can understand how these people feel, as I experienced it by myself",

"The knowledge of Braille and SL focused in dental practice"

"To analyse in detail which are the mistakes and offenses we make every day to people with sensory disabilities, and how to fix these mistakes and avoid these offenses"

"I think the most important part was the Role-Playing, because it gave me the chance to put myself in their shoes and understand their challenges. This encouraged me to learn Braille and SL beyond the evaluation, but it is something really necessary to learn, not just as professionals, but as persons",

"The fact that I can effectively communicate with the patients really had an impact on me, because I learnt the basics of Braille and SL"

Comments and suggestions from the students are shown in Table 4.

Table 4. Comments and suggestions from the students.

\begin{tabular}{ll}
\hline Suggestions & "This should be a mandatory subject in our academic education" (7); "More Braille and SL \\
& lessons" (2); "More interactions with PwD" (2) \\
& "A second part of the course" (2); "More spots available", \\
\hline & "I liked communicating with Blind and Deaf persons, and understanding what they feel, as I put \\
& myself in their place and learnt SL and Braille"; "I found the course a pleasant experience"; "I \\
& really enjoyed all the activities"; "It was very didactical, the topics weren't boring or anything \\
& like that"; "We learnt the contents in a very didactical way"; "It increased greatly my interest, it \\
& opened my eyes"; "The course was developed in a very good way, it is well implemented and \\
& coordinated"; "Above all, great human support" \\
\hline
\end{tabular}

\section{DISCUSSION}

A 17-week elective course was carried out in the first semester of Dentistry School with 14 students enrolled. All students passed the course with the highest score, and thus were able to define the medical approach to hearing and visual disability, recognize the cultural and linguistic aspects of people with visual disability and people with hearing disability and learn their means of communication. All these learning outcomes were assessed through practical activities and the participation of Deaf and blind teachers.
What students valued the most was the active presence of Deaf and blind people, because for most of them this was their first encounter with a Deaf or a blind person, and because they felt that they were the appropriate persons to teach about their own experience, difficulties and ways of communication. This elective course fulfils the Convention on the Rights of Persons with Disabilities statement, specifically on "Recognizing the valued existing and potential contributions made by persons with disabilities to the overall well-being and diversity of their communities..." and "Considering that persons with disabilities should have the opportunity to be 
actively involved in decision-making processes about policies and programmes, including those directly concerning them". ${ }^{12}$ The importance of the latter is that, even though there is an increasing number of training programs for healthcare students around the world for the care of Persons with Disabilities, none of them involves the active participation of Persons with Disabilities as teachers, which, in our case, promoted a real sense of inclusion. In this regard, role-play was a fulfilling experience, as most students felt that they learnt valuable information that impacted positively on their future interactions with Deaf or blind patients. This type of experience, which has been well documented by Rochester University, has been shown to have a similar effect on pharmacy and medical students. ${ }^{15,19,27}$

Based on the comments and suggestions, it can be inferred that the students enrolled on this course thinking it would be a rather traditional course, with lectures and written tests and exams. In contrast, they were pleased that the program had a more practical approach, with standardized patients, where their skills were tested through simulated situations with Deaf and blind persons, promoting reflective thinking. The visits to CESFAMs in their own community to identify the barriers a Deaf or a blind person may encounter were also a positive way to promote reflective thinking through the Case Method approach, as they later, on their own and with the teachers' guidance, were able to find a way to address them. ${ }^{22,23,28-30}$ It has been established that the Case Method approach promotes reflective thinking, resulting in confident and consciously competent students, and that standardized patients promote the skills required to offer a better service to patients who have disabilities. ${ }^{21-23,28-33}$

Moreover, the Case Method approach was a highly effective strategy, as students (guided by their tutor) were able to identify the barriers a person with visual or hearing impairment may encounter; this situation went beyond the planned scenario, as students identified barriers in the streets near the CESFAMs, and also investigated their access through means of transport, as in some CESFAMs the nearest bus stop was 6 blocks away. In the second stage, the students proposed a number of reasonable adjustments to the problems they had identified earlier. Reasonable adjustments, i.e. solutions that do not involve significant alterations to the structure or procedure aimed at removing barriers towards full participation, are of great importance since resources in Public Health Centers are very limited, and expensive or time-consuming solutions would be too impractical. ${ }^{12,24,34}$ The reasonable adjustments proposed by the students were shared with directors from the different CESFAMs, in order to give them ideas on how to address the barriers observed.

Regarding the guided discussion (movie analysis), students watched a movie about a deafblind girl, who with her determination and her teacher's assistance learnt to read and to sign, went to university and finally, got her degree. As this story is based on the famous biography of Hellen Keller, it was a great way to change the students' views of Persons with Disabilities, because during the discussion panel the students revealed that they were amazed to discover what Persons with Disabilities with assistance and determination can achieve. This situation helped the students to understand that Persons with Disabilities need to be empowered, that they are subjects of legal rights and not subjects of charity. ${ }^{12,35}$ This topic was also addressed in the article discussion, in which it was reinforced that the correct term is Persons with Disabilities, not deaf-mute, deaf-dumb, the blind or retarded, and that the current euphemism Special Care patients should not be used. ${ }^{12,25,35}$

Among the educational strategies used, WhatsApp was an excellent tool for fluent coordination. The teacher and students were able to share news and events related to People with Disabilities, and send videos regarding specific SL signs and pictures of Braille, and exchange information related to Deaf or blind people in a very informal environment. Also, as the nature of the course was elective, sometimes the established schedule had to be modified or suspended since tests or exams from core courses in the dental undergraduate program were prioritized. This was mitigated through the instant communication that 
WhatsApp allows, making it easy to arrange a solution between the students and the teachers. ${ }^{36}$

The main limitation is that this study was only conducted in one dental school and had a small sample size. Even though it was a small sample, having more than 14 students would affect the interaction between students and teachers, hindering both interaction and learning. ${ }^{37-39}$

Next year, it is expected to incorporate students from multiple undergraduate healthcare programs, so that a greater variety of healthcare disciplines can offer better opportunities to promote collaborative and interdisciplinary work. Also, it is planned to develop a second level of this course, in order to enhance the skills acquired by the students.

\section{ACKNOWLEDGEMENTS}

\section{Technical support:}

- Marcelo Figueroa \& Karen Sáez: Blind teachers

- Lorenzo Flores \& Katherinne Caorsi: Deaf teachers

- Andrea Lozano: Director of SENADIS (National Service for Disability)

- Shamyr Castro, Ajdunt Professor Universidade Federal Do Ceará, Brazil

Financial support: This study was funded by CONICYT FONDEF FONIS + MINSAL / XV CONCURSO DE INVESTIGACIÓN Y DESARROLLO EN SALUD, FONIS 2018 SA18I0116.

\section{CONFLICTS OF INTEREST STATEMENT}

The authors report no conflicts of interest.

\section{REFERENCES}

1. Johnston M. Models of disability. Psychologist 1996; 9:205-210.

2. WHO. International classification of functioning, disability and health (ICF) [Internet]. Geneva: World Health Organization; 2007.

3. World Health Organization. Disability and Health Fact Sheet No. 352. WHO, Geneva; 2015.

4. Bachman SS, Vedrani M, Drainoni ML, Tobias C, Maisels L. Provider perceptions of their capacity to offer accessible health care for people with disabilities. J Soc Work Disabil Rehabil 2006;17:130-136.

5. Altin KT, Alp F, Aydin SN, Çildir SK, Sandalli N. Improvement of oral health status in a group of students with visual impairment in Istanbul. Cumhuriyet Dent J 2019;22:83-91.

6. Murray CJ, Vos T, Lozano R, Naghavi M, Flaxman $\mathrm{AD}$, Michaud C, et al. Disability-adjusted life years (DALYs) for 291 diseases and injuries in 21 regions, 1990-2010: a systematic analysis for the Global Burden of Disease Study 2010. Lancet 2013;380:21972223.

7. Campos V. Barriers deaf patients face when receiving dental treatment. J Oral Res 2016;5:144-145.

8. Ladd P. Deaf Culture: In Search of Deafhood. Clevedon, England: Multilingual Matters Ltd. 2003.

9. Lučić B, Ostrogonac S, Vujnović N, Sečujski M.Educational applications for blind and partially sighted pupils based on speech technologies for Serbian. Scientific World J 2015;2015: 839252.

10. Virgili G, Acosta R, Bentley SA, Giacomelli G, Allcock C, Evans JR.Reading aids for adults with low vision. Cochrane Database Syst Rev 2013;10:CD003303.

11. Šepić B, Ghanem A, Vogel S. Braille Easy: Onehanded Braille Keyboard for Smartphones. Stud Health Technol Inform 2015; 217:1030-1035.

12. United Nations Human Rights Office of the High Commissioners. The Convention on the Rights of Persons with Disabilities Training Guide. Professional Training Series No. 19. New York and Geneva: United Nations; 2014.

13. Lock E. A workshop for medical students on deafness and hearing impairments. Acad Med 2003;78:1229-1234.

14. Hoang L, LaHousse SF, Nakaji MC, Sadler GR. Assessing deaf cultural competency of physicians and medical students. J Cancer Educ 2011;26:175-182.

15. Thew D, Smith SR, Chang C, Starr MM. The deaf strong hospital program: a model of diversity and inclusion training for first-year medical students. Acad Med 2012;87:1496.

16. Van Winkle LJ, Fjortoft N, Hojat M. Impact of a workshop about aging on the empathy scores of pharmacy and medical students. Am J Pharm Educ 2012;76:9.

17. Oliveira YCA, Costa GMC, Coura AS, de Oliveira Cartaxo R, de Franca ISX.Brazilian sign language in 
the training of nursing, physiotherapy and dentistry professionals in the state of Paraíba, Brazil. Interface 2012;16:995-1008.

18. Jones $T$, Cumberbatch K. Sign language in dental education-A new nexus. Eur $J$ Dent Educ 2018;22:143-150.

19. Mathews JL, Parkhill AL, Schlehofer DA, Starr MJ, Barnett S. Role-reversal exercise with deaf strong hospital to teach communication competency and cultural awareness. Am J Pharm Educ 2011;75:53.

20. Robey KL, Minihan PM, Long-Bellil LM, Hahn JE, Reiss JG, Eddey GE; Alliance for Disability in Health Care Education. Teaching health care students about disability within a cultural competency context. Disabil Health J 2013;6:271-279.

21. Iezzoni LI, Long-Bellil LM. Teaching About Disability: Involving Patients with Disabilities as Medical Educators. Disabil Health J 2012;5:136-139.

22. $\mathrm{Xu}$ J. Toolbox of teaching strategies in nurse education. Chin Nurs Res 2016;3:54-57.

23. Hendricson WD, Andrieu SC, Chadwick DG, Chmar JE, Cole JR, George MC, et al. ADEA Commission on Change and Innovation in Dental Education. Educational Strategies Associated with Development of Problem-Solving, Critical Thinking, and Self-Directed Learning. J Dent Educ 2006;70:925936

24. Ministerio de Planificación. Ley $\mathrm{N}^{\circ} 20.422$. Establece normas sobre igualdad de oportunidades e inclusión social de personas con discapacidad. Chile: Diario Oficial de la República de Chile; 2010.

25. Campos V. Who has special needs? J Oral Res 2017;6:285

26. Castro SS, Rowe M, Andrade LF, Cyrino EG. Developing competencies among health professions students related to the care of people with disabilities: a pilot study. Interface 2018;22:551-563.

27. Thew D, Smith SR, Chang C, Starr M. Deaf Strong Hospital: An Exercise in Cross-Cultural Communication for First Year Medical Students. Acad Med 2012;87:1496-1500.

28. Bush H, Bissell V. The evaluation of an approach to reflective learning in the undergraduate dental curriculum. Eur J Dent Educ 2008;12:103-110.

29. Ihm JJ, Seo DG. Does Reflective Learning with Feedback Improve Dental Students' Self-Perceived Competence in Clinical Preparedness? J Dent Educ 2016;80:173-182.
30. Thidemann IJ, Söderhamn O. High-fidelity simulation among bachelor students in simulation groups and use of different roles. Nurs Educ Today 2013;33:1599-1604.

31. Long-Bellil LM, Robey KL, Graham CL, Minihan PM, Smeltzer SC, Kahn P; Alliance for Disability in Health Care Education. Teaching medical students about disability: the use of standardized patients. Acad Med 2011;86:1163-170.

32. Sandars J. The use of reflection in medical education: AMEE guide no. 44. Med Teach 2009;31:685-695

33. Ericsson KA. Deliberate practice and the acquisition and maintenance of expert performance in medicine and related domains. Acad Med 2004;79:S70-81.

34. Finsterbusch C. La extensión de los ajustes razonables en el derecho de las personas en situación de discapacidad de acuerdo al enfoque social de derechos humanos. Ius et Praxis 2016;22:227-252.

35. Campos V, Cartes-Velásquez R. Health care of people with visual or hearing disabilities. Rev Md Chilie 2019;147(5):634-642.

36. Khan AA, Siddiqui AZ, Mohsin SF, Al Momani MM, Mirza EH. Impact of network aided platforms as educational tools on academic performance and attitude of pharmacology students. Pak J Med Sci 2017;33:1473-1478.

37. Corcodel N, Krisam J, Klotz AL, Deisenhofer UK, Stober T, Hassel AJ, Rammelsberg P, Zenthöfer A.Evaluation of small-group education on the shade determination ability of preclinical dental students-A controlled clinical trial. Eur J Dent Educ 2018;22:e582e587.

38. Steinert Y. Student perceptions of effective small group teaching. Med Educ 2004;38:286-293

Meo SA. Basic steps in establishing effective small group teaching sessions in medical schools. Pak J Med Sci 2013;29:1071-1076. 